\title{
SiC/Si composites elaboration by capillary infiltration of molten silicon
}

J. Roger ${ }^{\text {a, } *, ~ L . ~ G u e s n e t ~}{ }^{\text {a }}$, A. Marchais ${ }^{\text {b }}$, Y. Le Petitcorps ${ }^{\text {a }}$

a Université de Bordeaux, CNRS, Laboratoire des Composites ThermoStructuraux, UMR 5801, 33600 Pessac, France

${ }^{\mathrm{b}}$ Safran Ceramics, rue de Touban Les 5 chemins, 33185 Le Haillan, France

* Corresponding author: e-mail: jerome.roger@1cts.u-bordeaux.fr

\begin{abstract}
Infiltration of molten metal into ceramic performs without external pressure is a promising fabrication method for metal-matrix composites. Thus, this research is focused on the kinetic of capillary infiltration in the processing of $\mathrm{Si} / \mathrm{SiC}$ composites. The calculation of the infiltration kinetics for a liquid in a porous material is possible by applying the modified-Washburn equation which involves the effective diameter of the pores. This equation implies a $K$ value depending on the wetting angle, the density, the viscosity and the surface tension of the liquid at a given temperature. In this study, the main aim was to measure the $K^{\mathrm{Si}}$ value of molten silicon infiltration into porous $\mathrm{SiC}$ at $1500^{\circ} \mathrm{C}$. On this way, consolidated $\beta$-SiC powder compacts were prepared for infiltration experiments. The effects of the $\mathrm{SiC}$ particles presintering on the pore size were examined as they can affect molten silicon infiltration. So, the monitoring of the mass increase during hexadecane rise was used to determine the effective diameter of the pores. It was evidenced that an increase of $15.5 \%$ of the initial effective diameter occurs. Consequently, a corresponding correction has to be applied to the initial effective diameter of the siliconinfiltrated compacts. Infiltrations of pure molten silicon into $\mathrm{SiC}$ compacts were successfully carried out at $1500^{\circ} \mathrm{C}$ under high vacuum $\left(5.10^{-3} \mathrm{mbar}\right)$ and the average value of $K^{\mathrm{Si}}$ was found equal to $(5.8 \pm 0.4) \times 10^{-6} \mathrm{~cm}^{5}$.s.g $\mathrm{g}^{-2}$. The effect of molten silicon rise on the porosity was also considered.
\end{abstract}

Keywords: SiC; Silicon; Composites; Infiltration; Porosity; Washburn 


\section{Introduction}

The need for increasing the strength and the stiffness, and decreasing the weight of materials for transport and high temperature structural applications has attracted much activity in metal matrix composites. As proposed by Aghajanian et al., pressureless infiltration of liquid metals into packed ceramic particulates or fiber preforms is obviously an efficient process for the fabrication of this kind of composite [1-2]. It offers the potential to be an alternative, simple and low-cost processing route for the manufacture of ceramic reinforced metal matrix composites without remaining porosities. Recently, special interest has been focused on SiC ceramicreinforced metal-matrix composites. Indeed, $\mathrm{SiC}$ is important in a broad range of technological applications because of its good oxidation resistance, high thermal conductivity, low density, high stiffness and adequate toughness. $\mathrm{SiC}$ is a promising material for ceramic-matrix composites for the hot parts of the structures in engines [3,4]. It was demonstrated that high $\mathrm{SiC}$ volume fraction composites can be produced by infiltrating liquid metals into packed $\mathrm{SiC}$ powder. This way was applied at relative low temperatures with aluminum and copper $[5,6]$. These composites have a considerable benefit in electronic packaging and thermal management applications due to their low coefficient of thermal expansion, high thermal conductivity, high elastic modulus and improved wear resistance. But the poor wettability for pure $\mathrm{Cu}$ and pure $\mathrm{Al}$ on sintered $\mathrm{SiC}$ and severe interfacial reaction between the liquid and $\mathrm{SiC}$ grains are the main problems $[7,8]$. However, spontaneous infiltration is believed to be a promising route for the fabrication of $\mathrm{SiC}$ reinforced metal-matrix composites owing to its advantages of simple equipment, low cost and the near-to-shapes complex parts [9-12]. Silicon is commonly used as alloy element to copper and aluminum to enhance the wettability and to limit the reactivity between ceramic and liquid metal [6,12-14]. On this way, one can easily consider the possibility to use melt silicon as liquid metal. This way commonly called LSI (Liquid Silicon Infiltration) implies an elaboration temperature higher than the melting point of $\mathrm{Si}\left(1414^{\circ} \mathrm{C}\right)$. Some studies reported the feasibility and the interest of the LSI process $[15,16]$. Dense composites were thus obtained by infiltrating molten silicon between 1450 and $1600^{\circ} \mathrm{C}$ into porous preforms prepared from $\mathrm{SiC}$ powders. The $\mathrm{SiC}$ particles appear well preserved during the preparation of the composite. To optimize the LSI process, it is important to know the infiltration kinetic of molten 
silicon in porous $\mathrm{SiC}$ preforms. Up to now, no experimental measurements are available in literature about the capillary rise of molten silicon into this kind of material. In a previous paper we estimated the kinetic range of molten silicon infiltration in porous $\mathrm{SiC}$ from: 1) the physical data of the literature about liquid silicon; and 2) Washburn measurements with organic solvent [17]. But this method was not completely satisfying as the data about liquid silicon are strongly dispersed. Consequently, the aim of the present study is to investigate the kinetics of pressureless infiltration of molten silicon into $\mathrm{SiC}$ preforms by the in-situ measurement of the weight gain versus time. The effects of the $\mathrm{SiC}$ particles presintering on the pore size have been studied as they can affect the liquid infiltration. In this aim, the influence of the heating on the pore size of the $\mathrm{SiC}$ compacts is established by mercury porosimetry and by hexadecane capillary infiltration at room temperature. Then, a mathematical correction can be applied to the infiltration of molten silicon to establish the most accurate kinetic description of this process.

\section{Background on the capillary infiltration of silicon into porous $\mathrm{SiC}$}

Prior to experimental investigations, a preliminary thermodynamic analysis of the equilibrium in the Si-C system was performed with the help of the ThermoCalc software [18]. The relevant thermodynamic descriptions of this binary system reported by Grobner et al. was used for these calculations [19]. The so-calculated phase diagram is shown in Figure 1-a). The particularity of the $\mathrm{Si}-\mathrm{C}$ system is the formation of only one binary compound $\mathrm{SiC}$ which incongruently decomposes at a temperature of $2700^{\circ} \mathrm{C}$. At the working temperature of $1500^{\circ} \mathrm{C}$, silicon is in the liquid state and in equilibrium with $\mathrm{SiC}$. Furthermore, according to literature data, the maximum value of carbon solubility into liquid silicon at $1500^{\circ} \mathrm{C}$ is found equal to $170 \mathrm{ppm}$ in mass as shown in Figure 1-b) [19-23]. From this very low value, the interaction between pure molten silicon and $\mathrm{SiC}$ can be considered a priori as negligible. The capillary infiltration of liquids into porous materials depends on several factors influencing the experiments. These factors can be classified into four groups: (a) the particulates (size, shape, and volume fraction); (b) the liquid metal (density, surface tension and viscosity); (c) the liquid/solid interface (contact angle); and (d) the experimental conditions (applied pressure, time at pressure, temperature, and atmosphere in which the infiltration takes place). In the present case, the main difficulty is relative to the 
characteristic physical values of molten silicon. Indeed, several values are reported in literature for the surface tension [24-35], for the density [30,34-39] and the dynamic viscosity [30,35,40]. The contact angle of liquid silicon on $\mathrm{SiC}$ being reported close to $38^{\circ}$ at $1500^{\circ} \mathrm{C}$ [41]. As evidenced in Figure 2, the values relative to the surface tension, the density and the dynamic viscosity are very scattered. From these values, the capillary infiltration data can be analyzed using the Washburn equation (Equation 1) relative to the porosity radius: [42-45].

$\frac{d}{d t}\left(\pi \cdot r^{2} \cdot h \cdot \rho \cdot \frac{d h}{d t}\right)=\left(\frac{2 \cdot \sigma \cdot \cos \theta}{r}-\rho \cdot g \cdot h-\frac{8 \cdot \mu \cdot h}{r^{2}} \frac{d h}{d t}\right) \cdot \pi \cdot r^{2} \quad$ Equation 1

where $t$ is the time, $r$ is the medium radius of the pores, $h$ is the infiltration height, $\rho$ is the density, $\sigma$ is the surface tension, $\theta$ is the contact angle, and $\eta$ the dynamic viscosity. Equation 1 can be simplified in the case of small radii capillaries with creeping flow. Then, $d / d t(h \cdot d h / d t)$ is close to 0 . Equation 1 can be modified as follows [46]:

$$
\frac{8 \cdot \mu \cdot h}{r^{2}} \frac{d h}{d t}=\frac{2 \cdot \sigma \cdot \cos \theta}{r}-\rho \cdot g \cdot h \quad \text { Equation } 2
$$

For short durations, $\rho . g . h<<8 \mu . h / r^{2} \cdot d h / d t$, then it can be written:

$h^{2}=\frac{r \cdot \sigma \cdot \cos \theta}{2 \cdot \mu} \cdot t$ Equation 3

or:

$$
\frac{h^{2}}{t}=\frac{\sigma \cdot \cos \theta}{4 \cdot \mu} \cdot d_{\mathrm{eff}}
$$

Equation 4

where $d_{\text {eff }}$ is the effective diameter of the porosity equal to $2 r$. From the linear fit of the $h^{2}=f(t)$ curves, it is possible to determine the effective diameter $d_{\text {eff }}$ of the porosity. The mass increase during the infiltration of the liquid can also be used to calculate the value of the effective diameter $d_{\text {eff }}$ by modifying Equation 4:

$$
\frac{m^{2}}{t}=\frac{\sigma \cdot \cos \theta}{4 \cdot \mu} \cdot \rho^{2} \cdot \varepsilon^{2} \cdot S^{2} \cdot d_{\mathrm{eff}}
$$

Equation 5

where $m$ is the infiltrated mass of the liquid, $\rho$ is the density of the liquid, $\varepsilon$ is the initial porosity of the sample, and $S$ is the infiltration section obtained by multiplying the width and the thickness of the sample. Consequently, the infiltration kinetic of molten silicon depends directly 
on quantities that are not precisely established. We decided to define a characteristic quantity called $K$ corresponding to Equation 6:

$$
K=\frac{4 \cdot \mu}{\sigma \cdot \cos \theta \cdot \rho^{2}} \quad \text { Equation } 6
$$

On the basis of the previously mentioned data, one can identify the upper and lower values of the density, the surface tension and the dynamic viscosity of molten silicon at $1500^{\circ} \mathrm{C}$. From these extreme values, one can calculate the upper $K_{\max }$ and lower $K_{\min }$ limits of $K$. They are given in Table 1. The corresponding error on this quantity is of $30 \%$. It is consequently necessary to specify this characteristic quantity defining the infiltration kinetic of liquid silicon into porous $\mathrm{SiC}$ materials.

\section{Experimental procedures}

\subsection{Starting materials}

Commercial green $\beta$-SiC powder (99.8\% purity, Alfa Aesar GmbH \& Co KG, Germany) was used as raw material. This powder exhibits a bimodal distribution with a population centered at $0.2 \mu \mathrm{m}$ and a larger population centered between 1 and $2 \mu \mathrm{m}$ as shown in Figure 3. From the Xray diffraction pattern, $\mathrm{SiC}$ powder was found to contain mainly cubic 3C-SiC polytype ( $\beta$-SiC). The X-ray diffraction pattern of the powder, shown in Figure 3-c), exhibits two additional peaks at $2 \theta=34.182^{\circ}$ and $38.217^{\circ}$ corresponding to $6 \mathrm{H}-\mathrm{SiC}$ polytype $(\alpha-\mathrm{SiC})$. A high background intensity around the (111) peak at $2 \theta=35.644^{\circ}$ is moreover observed. As reported by Pujar and Cawley [47] these features are due to stacking faults in the powders and are not due to the presence of other polytypes. The porous SiC compacts were obtained from mixtures composed of $3 \mathrm{~g}$ of $\beta-\mathrm{SiC}$ powder and $1 \mathrm{~cm}^{3}$ of commercial ethanol as lubricant which were uniaxially pressed into rectangular specimens of about $50 \times 5 \times 5 \mathrm{~mm}^{3}$ at $100 \mathrm{MPa}$ using stainless steel die. Then, after drying in atmosphere for $12 \mathrm{~h}$, the green $\beta$-SiC compacts were presintered at $1400^{\circ} \mathrm{C}$ for $3 \mathrm{~h}$ under high vacuum $\left(2 \times 10^{-4} \mathrm{mbar}\right)$ to obtain strengthened porous $\mathrm{SiC}$ ceramics. Some compacts were cut in the length into two equivalent parts by using a fine diamond saw $(0.5 \mu \mathrm{m})$, the dimensions of these compacts were then close to $50 \times 5 \times 2 \mathrm{~mm}^{3}$. All compacts were settled by polishing with a precision of at least $100 \mu \mathrm{m}$ to homogenize the section. This stage is of 
importance as the capillary infiltration kinetic of a liquid depends on the cross section. One half of the compacts was used for the infiltration experiments of liquid silicon; the other half was used as a reference to identify the effects of the heat treatment on the porosities. Laboratory grade hexadecane provided by Sigma Aldrich Co. (USA) was used for the capillary infiltration experiments at $20^{\circ} \mathrm{C}$. Silicon of commercial purity (99.9999\%, Strem Chemicals, Inc., Germany) was used in the experiments. The melt silicon infiltration experiments were carried out in high vacuum $\left(5 \times 10^{-3} \mathrm{mbar}\right)$ at $1500^{\circ} \mathrm{C}$. In Table 1 we give the contact angle on $\mathrm{SiC}$, the dynamic viscosity, the density and the surface tension of hexadecane [48].

\subsection{Infiltration experiments of hexadecane solvent}

The capillary infiltration experiments were performed on a self-made equipment at $20^{\circ} \mathrm{C}$ in a temperature-regulated room. Figure 4-a) represents the experimental setup for the column of the wetting experiments and the visual aspect of a compact. The SiC compacts were hanged along their largest dimension to a modified analytical balance, which was connected to a computer. A crystallizer containing the solvent (hexadecane) was manually raised until the contact with the solvent. The mass variations were recorded up to 9000 seconds by steps of 1 second. The liquid height reached approximately one third of the total height of the samples. Losses due to solvent evaporation were measured and estimated to be less than $1 \%$ of the imbibed solvent mass and were hence considered as negligible. The time dependence of hexadecane infiltration in the SiC compacts was recorded by monitoring the weight gain. A typical curve of a compact is plotted in Figure 5-a). One can note that for the shortest durations, hexadecane rises very quickly in the blocks by capillary action. Then, the infiltration kinetic is lower for longer durations.

\subsection{Heat treatment and pressureless infiltration of liquid silicon}

The heat treatments with or without silicon capillary infiltration experiments were performed at $1500^{\circ} \mathrm{C}$ in a self-made equipment. The natural infiltration processing was carried out in an inductively heated furnace fitted with a graphite susceptor at a vacuum better than $5 \times 10^{-3} \mathrm{mbar}$. The temperature was regulated with a bichromatic pyrometer (Modeline 5, Ircon, USA). The temperature was increased to $1500^{\circ} \mathrm{C}$ at a heating rate of $20^{\circ} \mathrm{C} \cdot \mathrm{min}^{-1}$, kept constant for 15 
minutes to melt the silicon and to stabilize its temperature. Then, either the temperature is directly decreased at a rate of $30^{\circ} \mathrm{C} \cdot \mathrm{min}^{-1}$ or molten silicon is put in touch with the compact during 4 minutes to ensure a complete filling. The ensuing cooling is performed in the same manner than indicated above. The typical shape of silicon-infiltration curves is shown in Figure 5-b,c). In any cases, the graphite crucible, coated with a protective boron nitride (BN) layer, contained $8 \mathrm{~g}$ of silicon. This crucible was raised through an automatic jack controlled by a step motor system to keep the contact between the compact and the liquid. The SiC compacts were drilled to be hold with a graphite hanger and a SCS- $6^{\mathrm{TM}}$ fiber. This assembling is suspended to an analytical balance with a resolution of $0.3 \mu \mathrm{g}$ (ANR DS1070, Setaram Instrumentation, France) with a numerical record of the weight variation versus time every second. Figure 4-b) represents the schematic setup of the silicon infiltration experiments and the visual aspect of compacts not covered or covered with a BN layer applied by spraying (HeBoCoat 21E, Henze Boron Nitride Products AG, Germany). A BN layer limits the rise of the liquid along the faces. It was verified that the $\mathrm{BN}$ powder remains on-surface and do not penetrate into the compact.

\subsection{Characterization of the compacts}

The evolutions of the porosities and grains size distributions were scrutinized as any variation could have a noticeable effect on the rise of liquid silicon. Consequently, the porosities of the SiC compacts were determined from weight and geometric measurements at the consolidatedstate. The porosity $\varepsilon$ of the samples analyzed by mercury porosimetry (Autopore IV, Micromeritics Instrument Corp., USA) and by helium pycnometry (AccuPyc1340, Micromeritics Instrument Corp., USA) was calculated by applying the formula $\varepsilon=1-d_{\mathrm{a}} / d_{\mathrm{t}}$, with $d_{\mathrm{a}}$ the apparent density obtained from mercury porosimetry and $d_{\mathrm{t}}$ the true density measured from helium pycnometry for a sample volume of about $0.2 \mathrm{~cm}^{3}$. For the silicon-infiltrated compacts, infiltrated silicon was removed by immersing during $20 \mathrm{~h}$ in a bath made of 50 vol.\% of distilled water, 25 vol. $\%$ of nitric acid (37\% concentration) and 25 vol. $\%$ of hydrofluoric acid ( $40 \%$ concentration). The degradation of the $\mathrm{SiC}$ compacts by the acid etching was also examined. Thus, a consolidated and a heat-treated compact were also treated in the same way.

The pore size distribution was also measured by mercury porosimetry on the samples 
characterized by helium pycnometry. The microstructures of the resulting porous $\mathrm{SiC}$ ceramics and $\mathrm{SiC} / \mathrm{Si}$ composites were performed with a FEI Quanta 400FEG scanning electron microscopy (SEM) operated at $5 \mathrm{kV}$. The heat-treated and infiltrated compacts were cut and embedded in epoxy resin under vacuum. The cross-section was ground and polished to a $1 \mu \mathrm{m}$ diamond finish. From the SEM micrographs, it was possible to estimate the SiC particles sizes variation during the heat treatment prior to silicon infiltration and after it. Qin's method [49] was used by identifying the circumference of each particle and automatically determining the equivalent diameter of a circle of equal area with Image Analysis System (ImageJ) [50]. The successive steps of an image analysis consist in adjusting the threshold, determining the particle boundary outlines by using the Watershed analysis process implemented in ImageJ, setting the scale of the considered image; and finally realizing the analysis of the particles to obtain their surface and equivalent diameter. The curve plot of the cumulative surface fraction versus the normalized diameters $\left(d / d_{50}\right)$ is obtained by adding for each normalized diameter value the surface of the particles having at least the considered normalized diameter. Examples of soobtained micrographies are given in Figure 6-a) and Figures 7-a,b), these pictures corresponding respectively to Compact 0 , Compact 1 and Compact $\mathrm{A}$. It was found that $\mathrm{SiC}$ particles, bright grains in Figures 6-a) and 7-a) and dark grains in Figure 7-b), kept their original shape very well. From Figure 7-b), one can note the complete filling of the porosities by silicon. For each sample, at least 10000 particles were measured from several images. Considering the resolution and the background noise of the micrographics used in this study, the minimum surface threshold was found equal to $20000 \mathrm{~nm}^{2}$ corresponding to 20 neighboring pixels. The minimum equivalent diameter threshold of the measured particles is then equal to $80 \mathrm{~nm}$. An example of the $\mathrm{SiC}$ grains detection is given in Figure 6-b).

\section{Results and discussion}

\subsection{Effect of the heat treatment}

The effects of the increase, the dwell and the decrease of the temperature on the $\mathrm{SiC}$ compacts is of importance in this study because any evolution of the porosity rate and size has an effect on the infiltration kinetic of molten silicon. Indeed, the modified Washburn equation (Equation 5) 
depends on the porosity rate $\varepsilon$ and the effective diameter of the pores $d_{\text {eff. In the aim to }}$ determine the influence of the heat treatment, the reference samples called Compacts $0,1,2,3$ and 4 were analyzed by SEM to determine the $\mathrm{SiC}$ granular network. This was done by measuring the grains size distribution with the help of Image $J$ software in order to quantify the $d_{10}, d_{50}$ and $d_{90}$ characteristic values. Figure 8-a) shows an apparent unimodal distribution of the grain size distribution measured on a compact without any heat treatment. To maximize the reliability of these characterizations, the same analyses were realized on several images for all samples infiltrated or not by molten silicon. By this way, it was possible to plot the variations of the $d_{10}, d_{50}$ and $d_{90}$ values, as shown in Figure 8-b). It appears that no noticeable evolution occurs here independently of the sample. However, the consolidation effect generated during the heat treatment at $1400^{\circ} \mathrm{C}$ for $3 \mathrm{~h}$ is marker of a presintering process without densification since the dimensions of the compacts remain constant. The porosities of the samples measured by helium pycnometry and by geometrical measurements using the theoretical density of $\beta$-SiC i.e. $3.21{\mathrm{~g} . \mathrm{cm}^{-3}}^{-}$are mostly in good agreement. But, because of the smallness of the samples analyzed by helium pycnometry compared to the volume of the compacts, some results obtained from this method were inconsistent. It is also obvious that the compacts contain a given level of heterogeneity, the porosity fluctuating locally of a few percent within a given compact. This could be induced by the presence of less-packed areas or of some cracks generated within the green compacts. So, the porosity extracted from helium pycnometry is not completely relevant for the capillary infiltration analysis by Washburn model as this method implies the average porosity within a compact. That is why all the porosity values given here were obtained from the geometrical consideration. We assume that this approach is not completely satisfying but it constitutes the most convenient way in the present case. The average porosity of the as-prepared porous $\mathrm{SiC}$ compacts was found equal to $46 \pm 2 \%$, the porosity rates were stable whatever the applied heat treatment. Moreover, according to Equation 5 applied to hexadecane and molten silicon for a given compact, one can deduce a simplified relationship implying only the $K$ value of molten $\mathrm{Si}$ at $1500^{\circ} \mathrm{C}$, the $K$ value of hexadecane and the square weight variations for hexadecane and molten silicon per time unity. Consequently, a stable porosity has no direct influence on the quantification of the value of $K$ for molten silicon. Negligible mass and dimension variations were measured for all heated-treated compacts so that the porosity is 
considered as constant. The pore size distribution of the $\mathrm{SiC}$ consolidate-state compact (Compact 0) is shown in Figure 9. The pore size distribution of the porous $\mathrm{SiC}$ compacts presents a single peak with a narrow width, signifying a uniform pore size distribution centered on $0.26 \mu \mathrm{m}$. This pore distribution of the consolidated $\mathrm{SiC}$ compact also indicates that pores are all connected mutually to form an open pore-network. The heat treatment (HT) at $1500^{\circ} \mathrm{C}$ for 15 minutes applied to Compact 2 has a little effect on the pore size distribution with a very slight sliding of the peak towards higher values as shown in Figure 9. This could be justified by the progression of the sintering mechanism. From theses analyses, the effect of the heating on the porosity size of the $\mathrm{SiC}$ compacts is moderate. The variation of the effective diameter $d_{\text {eff }}$ during the heat treatment was also studied on Compacts 1,2, 3 and 4 by measuring its values on each sample before and after applying the heat treatment at $1500^{\circ} \mathrm{C}$ for $0.25 \mathrm{~h}$ without LSI. The hexadecane solvent was evaporated from the compacts in an oven at $100^{\circ} \mathrm{C}$ for $24 \mathrm{~h}$. As expected from the Washburn model, the plots of the normalized squared-mass gain of hexadecane rise linearly with time as shown in Figure 10-a) and Figure 10-b), corresponding, respectively, to the hexadecane infiltration before and after the heat treatment. These plots are normalized to the squared values of the porosity $(\varepsilon)$ and the section $(S)$ of the compacts according to Equation 5. The weight $\left(w_{\mathrm{m}}\right)$ and the time of formation $\left(t_{\mathrm{m}}\right)$ of the solvent meniscus were also deducted for a greater accuracy $[43,44,51]$. The effective diameter $d_{\text {eff }}$ is determined from the linear regression of these curves as the slopes are equal to $d_{\text {eff }} / K^{\text {hexadecane }}$. The soobtained $d_{\text {eff }}$ values of the four reference compacts before $\left(d_{\text {eff,initial }}\right)$ and after the heating at $1500^{\circ} \mathrm{C}$ for $0.25 \mathrm{~h}\left(d_{\mathrm{eff}, \mathrm{HT}}\right)$ are reported in Table 2 . From these values, it was determined that the effective diameters increase of about $15.5 \%$ during the heat treatment. Such a variation of the effective diameter must be taken into consideration for the silicon infiltration as it clearly affects the filling kinetic as demonstrated by the higher slopes in Figure 10-b) compared to the corresponding ones in Figure 10-a). It is probably a manifestation of the porosity size increase evidenced by mercury porosimetry. 


\subsection{Infiltration of liquid silicon}

Prior to molten silicon infiltration experiments, the initial effective diameters of Compacts A, B, $\mathrm{C}$ and $\mathrm{D}$ were determined by hexadecane infiltration. The corresponding curves of the normalized squared-mass gain versus the corrected time are shown in Figure 11-a). The initial effective diameters were deduced from the slopes of the curves and are reported in Table 3.

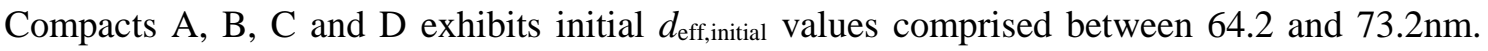
Those values are close to the ones of the reference compacts which are included in the 65.6 $71.8 \mathrm{~nm}$ range. This adequacy allows to apply the correction identified previously i.e. the effective diameters of the silicon-infiltrated compacts are multiplied by 1.155 to take into account the modification of these values during the heating, the corresponding values are called $d_{\text {eff,HT }}$ and are given in Table 3. Moreover, the images analyses performed on these samples after silicon melt infiltration show no evolution of the apparent particles distribution (Figure 8-b)). The silicon infiltration measurements were performed on the Compacts $\mathrm{A}, \mathrm{B}, \mathrm{C}$ and $\mathrm{D}$ at $1500^{\circ} \mathrm{C}$. The curve of Compact A without BN coating is shown in Figure 5-b). The curve of BN-coated Compact B is shown in Figure 5-c) which is similar to the curves of Compacts $\mathrm{C}$ and D also coated by BN. The most striking fact is the importance of the silicon meniscus mass which represents almost half of the mass gain at the saturation of Compact A. The meniscus weight is reduced for Compacts B, C and D thanks to the BN coatings. This indicates that liquid silicon progresses on the uncoated faces of the compacts and interferes with the capillary rise. The measures of infiltration have to be as much as possible corrected from this effect to be adequate for the kinetic analysis of silicon capillary rise. That is why, the three others Compacts

$\mathrm{B}, \mathrm{C}$ and D were BN-coated. Thus, Figure 11-b) shows the variation of the square-corrected mass gain $\left(\mathrm{m}-\mathrm{m}_{\text {meniscus }}\right)^{2}$ versus $\varepsilon^{2} \cdot S^{2} \cdot d_{\text {eff,HT. }}\left(\mathrm{t}-\mathrm{t}_{\mathrm{m}}\right)$, so that the slope of the curve corresponds to $1 / K$. The linear fits of the curves give satisfactory reliability factors. But, the shape and the slope of the curve of Compact A differ from the ones of the others silicon-infiltrated compacts. This measurement is decisively not convenient for analyzing the capillary rise of molten silicon because of the liquid spreading on the faces of the compact shown in Figure 4-b). So, it was not taken into account for the determination of the $K$ coefficient. The so-obtained $K^{\mathrm{Si}}$ coefficients are equal to $6.200 \times 10^{-6}, 5.889 \times 10^{-6}$ and $5.417 \times 10^{-6} \mathrm{~cm}^{5} . \mathrm{s}^{-\mathrm{g}^{-2}}$ for, respectively, Compacts B, C 
and $\mathrm{D}$. The average value was found equal to $K^{\mathrm{Si}}{ }_{\text {average }}=(5.8 \pm 0.4) \times 10^{-6} \mathrm{~cm}^{5} \cdot \mathrm{s}^{-\mathrm{g}^{-2}}$ for an operating temperature of $1500^{\circ} \mathrm{C}$. This value is included within the limits of the extreme values $K_{\min }$ and $K_{\max }$ evaluated from the literature data (Table 1). As previously reported, liquid silicon promotes the growth of $\mathrm{SiC}$ crystals by dissolution-reprecipitation, what may induce an evolution of the pores during and after their filling by the liquid [52]. It is of importance to consider such a behavior as it obviously influences the infiltration kinetic. In order to reveal the prospective existence of this effect, the infiltrated silicon was removed from the SiC compacts by acid etching. Thus, the true porosity and the distribution of the pore size are determined from helium pycnometry and mercury porosimetry. Moreover, from these analyses, a more detailed description of the porosity shape can be applied. Indeed, for a capillary tube, the effective diameter corresponds to the real diameter. However, for a porous medium, the effective diameter is the size of an equivalent capillary having the same behavior. Some attempts have been made to theoretically model the effect of multiple radii and interconnections on capillarity flow. Dullien et al. [53-54] suggested the following equation:

$d_{\mathrm{eff}}=\frac{1}{3}\left[\sum_{\mathrm{k}}^{\mathrm{n}} d_{\mathrm{k}}\right]^{2} \cdot\left[\sum_{\mathrm{k}}^{\mathrm{n}} d_{\mathrm{k}} \cdot \sum_{\mathrm{j}}^{\mathrm{n}}\left(\frac{d_{\mathrm{k}}}{d_{\mathrm{j}}}\right)^{3}\right]^{-1}$

Equation 7

where $n$ is the number of different capillary sizes present in the unit cell of the equivalent porous medium and $d_{\mathrm{k}}$ and $d_{\mathrm{j}}$ are the corresponding diameters. For a packed powder, a two-sizes model is considered as sufficient to describe the porosity with accuracy [55]. The equation for a two-size capillary model is:

$d_{\text {eff }}=\frac{1}{3}\left(d_{\text {neck }}+d_{\text {bu lg }}\right)^{2} \cdot\left(d_{\text {neck }} \cdot\left(1+\left(\frac{d_{\text {neck }}}{d_{\text {bu lg e }}}\right)^{3}\right)+d_{\text {bu lge }} \cdot\left(1+\left(\frac{d_{\text {bu lg }}}{d_{\text {neck }}}\right)^{3}\right)\right)^{-1} \quad$ Equation 8

where $d_{\text {neck }}$ is the pore neck diameter and $d_{\text {bulge }}$ is the pore bulge diameter. A schematic representation of this model is given in Figure 12. The effective diameter $d_{\text {eff }}$ is obtained from solvent impregnation experiments, and the neck diameter $d_{\text {neck }}$ is determined from the mercury intrusion measurements. The neck diameter is the smallest pore diameter obtained for half of the mercury saturation [53]. To established the effect of liquid silicon and acid etching on the $d_{\text {bulge }}$ and $d_{\text {neck }}$ values, compacts with and without heat treatment and/or acid etching were also examined by this way. The corresponding $d_{\text {eff, }}, d_{\text {bulge }}$ and $d_{\text {neck }}$ values are reported in Table 3 . In 
this case, it was possible to determine the porosity by combining helium pycnometry and mercury porosimetry results as earlier described. As demonstrated by the analyses on Compact 0, a good agreement between porosity from geometrical measurements and the porosity obtained from helium pycnometry and mercury porosimetry. The effect of acid etching is found negligible on consolidated Compact 5 as the porosity rates are close. For the heat-treated Compact 2 and for the heat-treated and acid-etched Compact 1, the porosity varies in a not significant way. The comparison of Compact 0 and Compact 2 indicates an increase of both $d_{\text {bulge }}$ and $d_{\text {neck }}$ values, this is coherent with the effect of the presintering without densification. The influence of the acid etching is evidenced by comparing the $d_{\text {bulge }}$ and $d_{\text {neck }}$ values of Compact 0 and 5 but also the ones of Compact 1 and 2. In each case, an increase of these values is revealed, what is in adequacy with the shifting of the pore-size distribution to larger sizes (Figure 9). This demonstrates that the acid etching modifies slightly the size of the pores. At this stage, it is found that both the heat treatment and the acid etching increase the $d_{\text {bulge }}$ and $d_{\text {neck }}$ values. When considering the evolution of these values for the silicon-infiltrated compacts, i.e. Compacts $\mathrm{C}$ and $\mathrm{D}$, the so-obtained values are quite similar and are larger than the ones of Compact 1 which was only heat-treated and acid-etched. So, the corresponding gap could be attributed to the influence of molten silicon. As no variation of the apparent grain size could be evidenced after silicon filling (Figure 8-b)), this effect can be reasonably awarded to the grains ripening by transport of carbon atoms through the liquid. It should be noted that the pore-size distributions of these two silicon-infiltrated compacts are shifted to larger values with a significant increase of the distribution asymmetry (Figure 9). This behavior must be confirmed and more carefully examined as it may affect the capillary rising by modifying the shape of the pores.

\section{Conclusion}

The kinetic of molten silicon capillary infiltration was investigated through $\beta$-SiC powder compacts. Therefore, the main aim was to refine the value of the $K^{S i}$ constant characteristic of molten silicon infiltration into porous $\mathrm{SiC}$ materials at $1500^{\circ} \mathrm{C}$. As expected, the monitoring of the mass increases during silicon infiltration in packed-SiC powder is a convenient method for characterizing the porosity by applying the Washburn-modified equation. In this way, the 
effective diameter of the porosity in $\mathrm{SiC}$ compacts can be obtained by infiltrating hexadecane as fully wetting solvent. It was evidenced that a correction relative to the impact of the heating on the effective diameter is required. Thus, the variation of the effective diameter was examined on four $\mathrm{SiC}$ compacts during the heating preceding the LSI. An average increase of $15.5 \%$ of the effective diameter was measured corresponding to a noticeable increase of the mean pore size without variations of the porosity rate and the particulate network. The corresponding correction was applied to the initial effective diameter of the silicon-infiltrated compacts. It was identified that a coating of $\mathrm{BN}$ as a non-wetting medium must be applied on the sides of the compacts prior to the LSI to prevent the spreading of the liquid on these faces. From the LSI experiments realized on the three $\mathrm{BN}$-coated compacts it was confirmed the validity of the Washburn model for the rise of liquid silicon. Consequently, the average value of the $K^{\mathrm{Si}}$ constant was found equal to $(5.8 \pm 0.4) \times 10^{-6} \mathrm{~cm}^{5} . \mathrm{s.g}^{-2}$ at $1500^{\circ} \mathrm{C}$. So, it was possible by this approach to succeed in refining the value of this quantity which is of importance for the development of siliconinfiltrated materials. The examination of the effect of the heat treatment and silicon rise on the pore size distribution was realized by applying the Dullien model providing a more significant description of the pores. This model was applied with two characteristic diameters, defined as the bulge and neck diameters of the porosity. By this way, a probable influence of liquid silicon on the pore distribution was revealed. This fact must be examined with more attention in further works. 


\section{References}

[1] M.K. Aghajanian, N.H. Macmillan, C.R. Kennedy, S.J. Luszcz, R. Roy, Properties and microstructures of Lanxide $\mathrm{Al}_{2} \mathrm{O}_{3}-\mathrm{Al}$ ceramic composite materials, J. Mater. Sci. 24 (1989) 658-670.

[2] M.K. Aghajanian, M.A. Rocazella, J.T. Burke, S.D. Keck, The fabrication of metal matrix composites by a pressureless infiltration technique, J. Mater. Sci. 26 (1991) 447-454.

[3] K.K. Chawla, Ceramic Matrix Composites, second ed., Kluwer Academic Publishers, Boston, 2003, pp. 417-419.

[4] N.P. Bansal, Hand Book of Ceramic Composites, Kluwer Academic Publishers, Boston, 2005, pp. 117-147

[5] H. Sharifi. M.R. Nasresfahani, Investigation into the kinetic behavior of molten aluminum pressureless infiltration into SiC performs, Int. J. Mater. Res. 107 (2016) 954-959.

[6] K. Zhang, Z. Shi, G. Liu, G. Qiao, SiC/Cu composite prepared by spontaneous infiltration of copper alloy into porous SiC ceramic, Mater. Sci. For. 814 (2015) 569-573.

[7] L. Zhang, X. Qu, B. Duan, X. He, M. Qin, X. Lu, Preparation of $\mathrm{SiC}_{\mathrm{p}} / \mathrm{Cu}$ composites by Tiactivated pressureless infiltration, Trans. Nonferrous Met. Soc. China 18 (2008) 872-878.

[8] J. Chen, C. Hao, J. Zhang, Fabrication of 3D-SiC network reinforced aluminum-matrix composites by pressureless infiltration, Mater. Lett. 60 (2006) 2489-2492.

[9] J. Liu, Z. Zheng, J. Wang, Y. Wu, W. Tang, J. Lu, Pressureless infiltration of liquid aluminum alloy into SiC preforms, J. Alloys Compd. 465 (2008) 239-243.

[10] S.B. Ren, X.H. Qu, J. Guo, X.B. He, M.L. Qin, X.Y. Shen, Net-shape forming and properties of high volume fraction $\mathrm{SiC}_{\mathrm{p}} / \mathrm{Al}$ composites, J. Alloys Compd. 484 (2009) 256262.

[11] Y.H. Dong, X.B. He, L. Xu, X.H. Qu, Fabrication and thermal conductivity of near-netshaped diamond/copper composites by pressureless infiltration, J. Mater. Sci. 46 (2011) $3862-3867$.

[12] M.I. Pech-Canul, M.M. Makhlouf, Processing of $\mathrm{Al}-\mathrm{SiC}_{\mathrm{p}}$ metal matrix composites by pressureless infiltration of $\mathrm{SiC}_{\mathrm{p}}$ preforms, J. Mater. Syn. Process. 8 (2000) 35-53.

[13] M.A. Martinez, A. Martin, J.L. Lorca, Wear of Al-Si alloys and Al-Si/SiC composites at ambient and elevated temperature, Scripta Metall. Mater. 28 (1993) 207-212. 
[14] J.C. Lee, J.Y. Byun, S.B. Park, H.I. Lee, Prediction of Si contents to suppress the formation of $\mathrm{Al}_{4} \mathrm{C}_{3}$ in the $\mathrm{SiC}_{\mathrm{p}} / \mathrm{Al}$ composite, Acta Mater. 46 (1998) 1771-1780.

[15] C. Zollfrank, H. Sieber, Microstructure Evolution and Reaction Mechanism of Biomorphous Si/SiC Ceramics, J. Am. Ceram. Soc. 88 (2005) 51-58.

[16] D. Zhu, M. Gao, S. Zhang, H. Wu, Y. Pan, Y. Liu, H. Pan, F.J. Oliveira, J.M. Vieira, A high-strength $\mathrm{SiC}_{\mathrm{w}} / \mathrm{SiC}-\mathrm{Si}$ composite derived from pyrolyzed rice husks by liquid silicon infiltration, J. Mater. Sci. 47 (2012) 4921-4927.

[17] A. Marchais, J. Roger, Y. Le Petitcorps, Capillary infiltration of hexadecane in packed SiC powder and in $\mathrm{SiC} / \mathrm{SiC}$ preforms: Pore description and calculation of molten Si infiltration, Ceram. Inter. 42 (2016) 7774-7780.

[18] J. Andersson, T. Helander, L. Höglund, P. Shi, B. Sundman, Thermo-Calc and Dictra, Calphad 26 (2002) 273-312.

[19] J. Grobner, H.L. Lukas, F. Aldinger, Thermodynamic calculation of the ternary system AlSi-C, Calphad 20 (1996) 247-254.

[20] K. Yanaba, M. Akasaka, M. Takeuchi, M. Watanabe, T. Narushima, Y. Igushi, Solubility of carbon in liquid silicon equilibrated with silicon carbide, Mater. Trans. 38 (1997) 990994.

[21] R.N. Hall, Electrical contacts to silicon carbide, J. Appl. Phys. 29 (1958) 914-917.

[22] R.I. Scace, G. A. Slack, Solubility of carbon in silicon and germanium, J. Chem. Phys. 30 (1959) 1551-1555.

[23] H. Dalaker, M. Tangstad, Time and temperature dependence of the solubility of carbon in liquid silicon equilibrated with silicon carbide and its dependence on boron levels, Mater. Trans. 50 (2009) 1152-1156.

[24] W.D. Kingery, M. Humenik Jr., Surface tension at elevated temperatures. I. Furnace and method for use of the sessile drop method; surface tension of silicon, iron and nickel, J. Phys. Chem. 57 (1953) 359-363.

[25] B.A. Baum, P.V. Geld, E.S. Levin, Effect of temperature and composition on the density and surface energy of chromium-silicon alloys, Russ. J. Phys. Chem. 40 (1966) 795-798.

[26] Y.V. Naidich, V.M. Perevertailo, L.P. Obushchak, The surface properties of binary melts formed by gold with germanium and silicon, Russ. J. Phys. Chem. 49 (1975) 917-918. 
[27] S.C. Hardy, The surface tension of liquid silicon, J. Cryst. Growth 69 (1984) 456-460.

[28] K. Mukai, Z. Yuan, K. Nogi, T. Hibiya, Effect of the oxygen partial pressure on the surface tension of molten silicon and its temperature coefficient, ISIJ Int. 40 (2000) S148-S152.

[29] M. Przyborowski, T. Hibiya, M. Eguchi, I. Egry, Surface tension measurement of molten silicon by the oscillating drop method using electromagnetic levitation, J. Cryst. Growth 151 (1995) 60-65.

[30] Z. Zhou, S. Mukherjee, W.K. Rhim Measurement of thermophysical properties of molten silicon using an upgraded electrostatic levitator, J. Cryst. Growth 257 (2003) 350-358.

[31] F. Millot, V. Sarou-Kanian, J.C. Rifflet, B. Vinet, The surface tension of liquid silicon at high temperature, Mater. Sci. Eng. A 495 (2008) 8-13.

[32] Z.F. Yuan, K. Mukai, W.L. Huang, Surface tension and its temperature coefficient of molten silicon at different oxygen potentials, Langmuir 18 (2002) 2054-2062.

[33] S.I. Chung, K. Izunome, A. Yokotani, S. Kimura, Estimation of surface tension of molten silicon using a dynamic hanging drop, Jpn. J. Appl. Phys. 34 (1995) L631.

[34] W.K. Rhim, S.K. Chung, A.J. Rulison, R.E. Spjut, Measurements of thermophysical properties of molten silicon by a high-temperature electrostatic levitator, Int. J. Thermophys. 18 (1997) 459-469.

[35] W.K. Rhim, K. Ohsaka, Thermophysical properties measurement of molten silicon by high-temperature electrostatic levitator: density, volume expansion, specific heat capacity, emissivity, surface tension and viscosity, J. Cryst. Growth 208 (2000) 313-321.

[36] V.M. Glazov, S.N. Chizhevskai, N.N. Glagoleva, Liquid semiconductors. Plenum Press, 1969.

[37] M. Langen, T. Hibiya, M. Eguchi, I. Egry, Measurement of the density and the thermal expansion coefficient of molten silicon using electromagnetic levitation, J. Cryst. Growth 186 (1998) 550-556.

[38] H. Sasaki, E. Tokizaki, K. Terashima, S. Kimura, Density Variation of Molten Silicon Measured by an Improved Archimedian Method, Jpn. J. Appl. Phys. 33 (1994) 3803-3807.

[39] K. Ohsaka, S.K. Chung, W.K. Rhim, J.C. Holzer, Densities of Si determined by an image digitizing technique in combination with an electrostatic levitator, Appl. Phys. Lett. 70 (1997) 423-425. 
[40] Y. Sato, Y. Kameda, T. Nagasawa, T. Sakamoto, S. Moriguchi, T. Yamamura, Y. Waseda, Viscosity of molten silicon and the factors affecting measurement, J. Cryst. Growth 249 (2003) 404-415.

[41] P. Nikolopoulos, S.A.P. Los, G.N. Angelopoulos, A. Naoumidis, H. Grübmeier, Wettability and interfacial energies in SiC-liquid metal systems, J. Mater. Sci. 27 (1992) $139-145$.

[42] P. Sangsuwan, S.N. Tewari, J.E. Gatica, M. Singh, R. Dickerson, Reactive infiltration of silicon melt through microporous amorphous carbon preform, Metall. Mater. Trans. B 30 (1999) 933-944.

[43] D.V. Trong, J. Hupka, Characterization of porous materials by capillary rise method, Physicochem. Probl. Min. Process. 39 (2005) 47-65.

[44] M. Abraham, D.C. Ruben, Characterization of porous media by the kinetics of liquid penetration: vertical capillaries model, J. Colloid Inter. Sci. 189 (1997) 299-304.

[45] S.G. Advani, E.M. Sozer, Process Modeling in composite Manufacturing, fifteen ed., Marcel Dekker, New York, 2003.

[46] S. Kumar, A. Kumar, A. Shukla, A.K. Gupta, R. Devi, Capillary infiltration studies of liquids into 3D-stitched $\mathrm{C}-\mathrm{C}$ preforms Part A: Internal pore characterization by solvent infiltration, mercury porosimetry, and permeability studies, J. Eur. Ceram. Soc. 29 (2009) 2643-2650.

[47] V.V. Pujar, J.D. Cawley, Effect of stacking faults on the X-ray diffraction profiles of $\beta$-SiC powders, J. Am. Ceram. Soc. 78 (1995) 774-782.

[48] U. Onken, J. Rarey-Nies, J. Gmehling, The Dortmund Data Bank: a computerized system for retrieval, correlation, and prediction of thermodynamic properties of mixtures, Int. J. Thermophys. 10 (1989) 739-747.

[49] Y. Qin, G. Götz, W. Blum, Z.G. Zhu, Determination of size distribution of precipitates in the cast martensitic steel G-X12CrMoWVNbN 10-1-1 by direct and indirect method, J. Alloys Compd. 352 (2003) 260-264.

[50] C.A. Schneider, W.S. Rasband, K.W. Eliceiri, NIH Image to ImageJ: 25 years of image analysis, Nature methods 9 (2012) 671-675.

[51] E.W. Washburn, The dynamics of capillary flow, Phys. Rev. 17 (1921) 273-283. 
[52] J. Roger, A. Marchais, Y. Le Petitcorps, Examination of the interaction between liquid silicon and bulk silicon carbide, J. Crys. Growth 426 (2015) 1-8.

[53] F.A.L. Dullien, M.S. El-Sayed, V.K. Batra, Rate of capillary rise in porous media with nonuniform pores, Journal Colloid Interface Sci. 60 (1977) 497-506.

[54] F.A.L. Dullien, Porous Media: Fluid Transport and Pore Structure, Academic, New York, 1979.

[55] P.C. Carman, Flow of gases through porous media, first ed., Butterworths Scientific Publications, London, 1956. 
Table 1: Physical properties of hexadecane at $20^{\circ} \mathrm{C}$ and liquid silicon at $1500^{\circ} \mathrm{C}[27,30,35,37,48]$

\begin{tabular}{|c|c|c|c|}
\hline Physical properties & Hexadecane $\left(20^{\circ} \mathrm{C}\right)$ & \multicolumn{2}{|c|}{ Liquid silicon $\left(1500^{\circ} \mathrm{C}\right)$} \\
\hline Contact angle on $\beta$-SiC $\left({ }^{\circ}\right)$ & 0 & \multicolumn{2}{|c|}{38} \\
\hline Dynamic viscosity $\eta\left(\mathrm{g} \cdot \mathrm{cm}^{-1} \cdot \mathrm{s}^{-1}\right)$ & $3.04 \times 10^{-2}$ & $5.1 \times 10^{-3}$ & $7.4 \times 10^{-3}$ \\
\hline Density $\rho\left(\mathrm{g} . \mathrm{cm}^{-3}\right)$ & 0.77 & 2.565 & 2.490 \\
\hline Surface tension $\sigma\left(\mathrm{g} \cdot \mathrm{s}^{-2}\right)$ & 27.42 & 860.9 & 715.7 \\
\hline$K\left(\mathrm{~cm}^{5} . \mathrm{s}^{\mathrm{g}} \mathrm{g}^{-2}\right)$ & $7.48 \times 10^{-3}$ & $K_{\min }=4.58 \times 10^{-6}$ & $K_{\max }=8.46 \times 10^{-6}$ \\
\hline
\end{tabular}

Table 2: $d_{\text {eff }}$ initial values and $d_{\text {eff }}$ values after a heat treatment at $1500^{\circ} \mathrm{C}$ for $0.25 \mathrm{~h}$ of the reference samples to determine the $d_{\text {eff }}$ average variation

\begin{tabular}{|c|c|c|c|c|}
\hline Samples & $d_{\text {eff,initial }}(\mathrm{nm})$ & $d_{\text {eff, } \mathrm{HT}}(\mathrm{nm})$ & $\Delta d_{\text {eff }} / d_{\text {eff, initial }}(\%)$ & $\begin{array}{l}\text { Mean } d_{\text {eff }} \\
\text { variation }\end{array}$ \\
\hline Compact 1 & 65.6 & 75.4 & 14.9 & \\
\hline Compact 2 & 71.8 & 83.7 & 16.6 & \\
\hline Compact 3 & 66.1 & 76.8 & 16.2 & $+15.5 \%$ \\
\hline Compact 4 & 70.2 & 80.3 & 14.4 & \\
\hline
\end{tabular}


Table 3: Porosity and values of $d_{\text {eff, }}, d_{\text {bulge }}$ and $d_{\text {neck }}$ of the compacts depending on the applied treatments

\begin{tabular}{|c|c|c|c|c|c|c|c|c|}
\hline $\begin{array}{l}\text { Samples } \\
\text { (Successive } \\
\text { treatments) }\end{array}$ & $\begin{array}{c}\text { Dimensions } \\
\text { (mm) }\end{array}$ & Poros & $\mathrm{Hg} / \mathrm{He}$ & $\begin{array}{c}d_{\text {eff,Initial }} \\
\text { (nm) }\end{array}$ & $\begin{array}{l}d_{\mathrm{eff}, \mathrm{HT}} \\
(\mathrm{nm})\end{array}$ & $\begin{array}{l}d_{\text {eff,AE }} \\
(n m)\end{array}$ & $\begin{array}{l}d_{\text {bulge }} \\
(\mathrm{nm})\end{array}$ & $\begin{array}{l}d_{\text {neck }} \\
(\mathrm{nm})\end{array}$ \\
\hline Compact 0 & $50.00 \times 5.18 \times 5.67$ & 46.6 & 46.5 & 72.1 & - & - & 375 & 259 \\
\hline Compact 1 (HT/AE) & $49.27 \times 5.55 \times 2.17$ & 43.8 & 42.9 & 65.6 & 75.4 & 84.9 & 503 & 329 \\
\hline Compact 2 (HT) & $50.28 \times 5.64 \times 2.38$ & 44.2 & 45.1 & 71.8 & 83.7 & - & 424 & 296 \\
\hline Compact 3 (HT) & $50.05 \times 5.36 \times 4.81$ & 46.8 & - & 66.1 & 76.8 & - & - & - \\
\hline Compact 4 (HT) & $49.80 \times 5.31 \times 4.94$ & 44.7 & - & 70.2 & 80.3 & - & - & - \\
\hline Compact 5 (AE) & $47.24 \times 4.97 \times 4.82$ & 50.0 & 48.7 & 92.8 & - & 101.8 & 435 & 329 \\
\hline Compact A (LSI) & $49.95 \times 4.95 \times 1.92$ & 46.2 & - & 64.2 & 74.2 & - & - & - \\
\hline Compact B (LSI) & $50.42 \times 5.62 \times 2.43$ & 44.9 & - & 65.5 & 75.7 & - & - & - \\
\hline Compact C (LSI/AE) & $49.74 \times 5.04 \times 2.29$ & 47.6 & 44.7 & 73.2 & 84.5 & 92.7 & 612 & 384 \\
\hline Compact D (LSI/AE) & $50.14 \times 4.94 \times 4.16$ & 48.0 & 46.7 & 71.2 & 82.3 & 93.5 & 611 & 385 \\
\hline
\end{tabular}

$\left(\mathrm{HT}=\right.$ Heat Treatment at $1500^{\circ} \mathrm{C}$ for $0.25 \mathrm{~h}, \mathrm{AE}=$ Acid Etching, $\mathrm{LSI}=$ Liquid Silicon Infiltration $)$ 


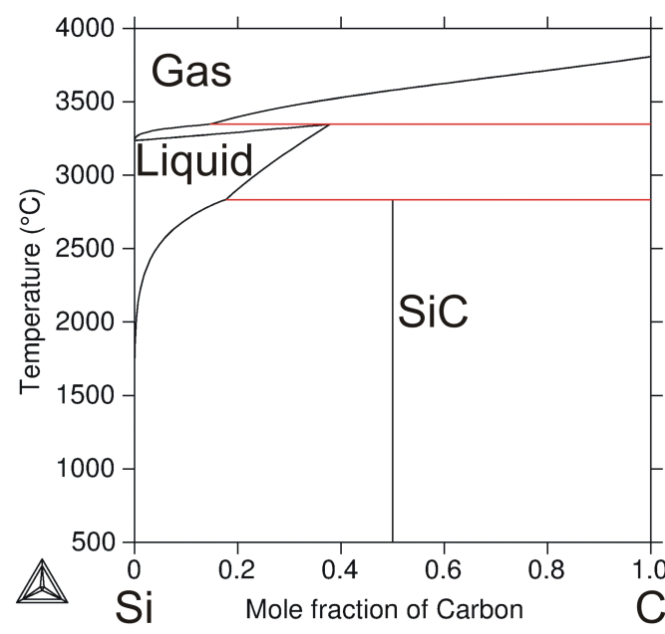

a)

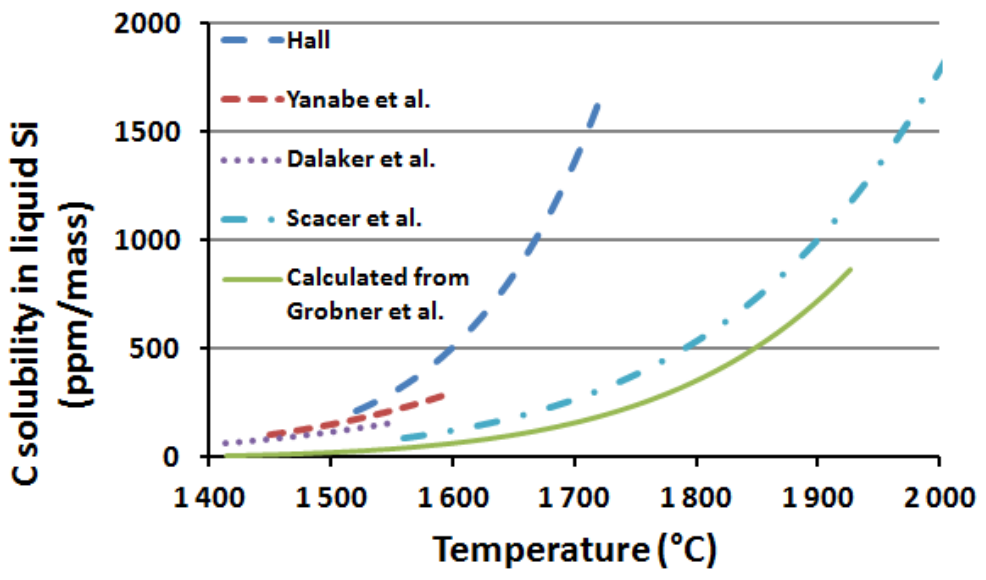

b)

Figure 1. Si-C system: a) calculated Si-C diagram [18,19] and b) solubility of carbon in molten silicon from literature [19-23]. The values from Grobner et al. were calculated by using ThermoCalc software [18].

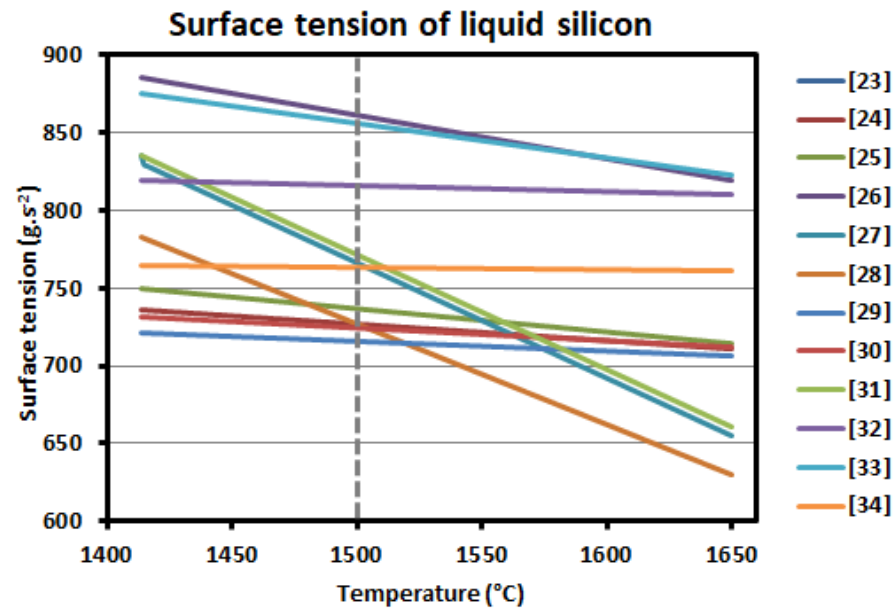

a)

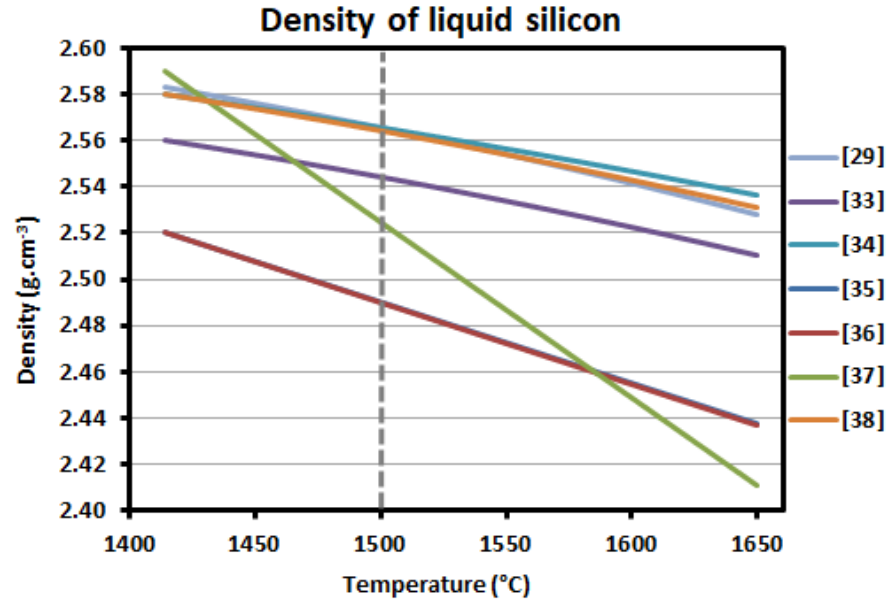

b)

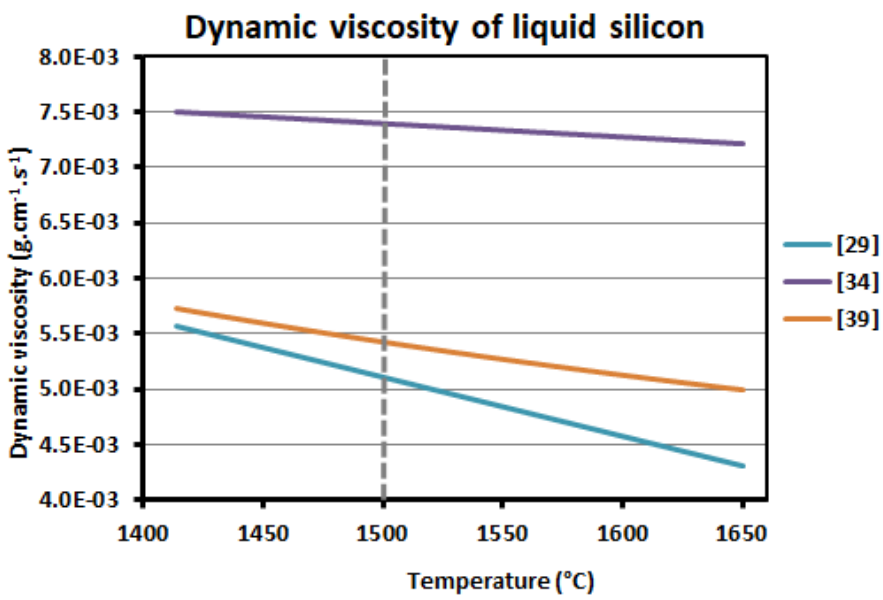

c)

Figure 2: Characteristic physical variables of liquid silicon versus temperature: a) surface tension [24-35], b) density [30,34-39] and c) dynamic viscosity [30,35,40]. 


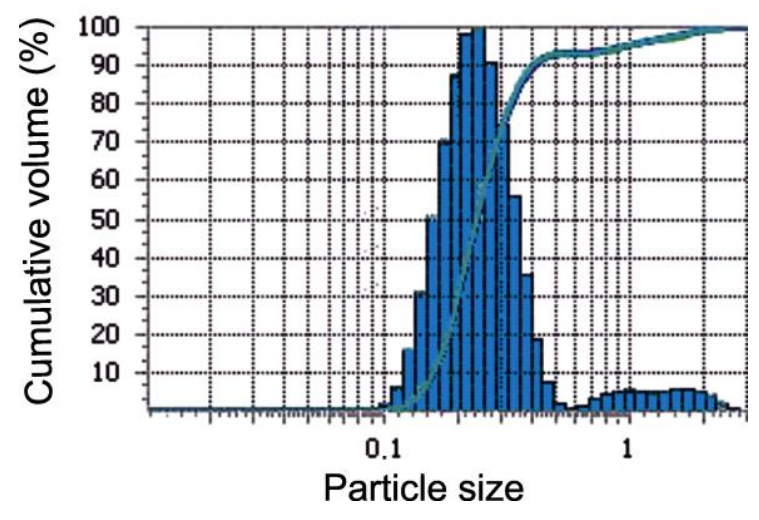

a)

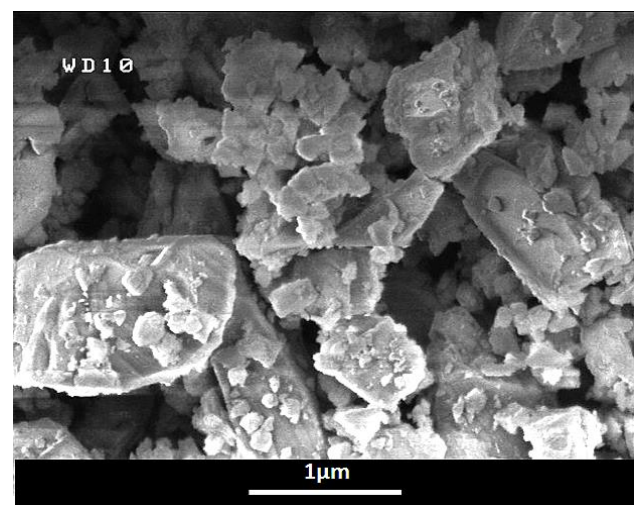

b)

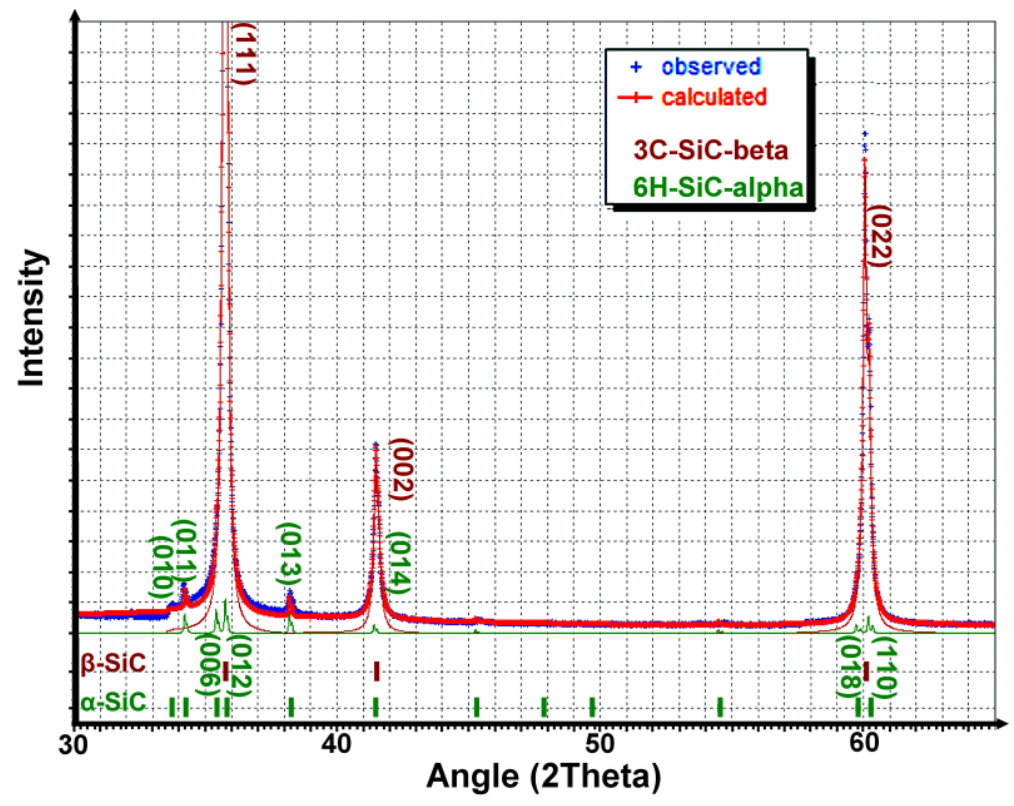

c)

Figure 3: Starting SiC powder:

a) grain size distribution, b) secondary electrons image (magnification $\times 30000$ ); and c) X-ray diffraction pattern $\left(\mathrm{K}_{\alpha} \mathrm{Cu}\right)$.

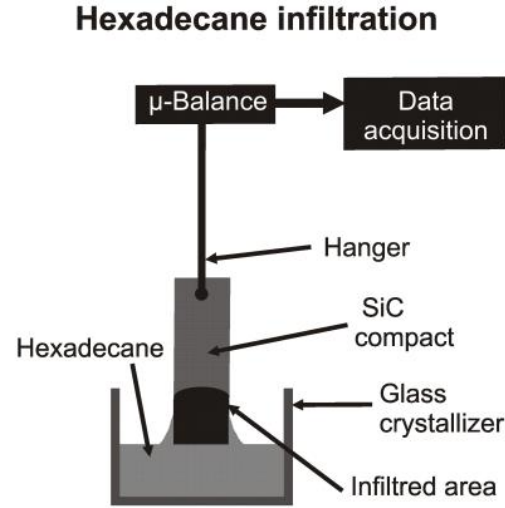

a)

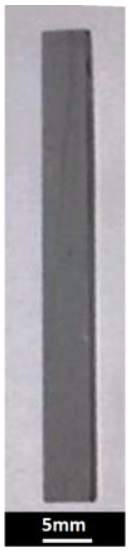

Figure 4: Schematics of the experimental set-up for the capillary rise tests in SiC compacts: a) with hexadecane solvent and b) with molten silicon at $1500^{\circ} \mathrm{C}$. Samples pictures from the left to the right correspond to Compact 1, Compacts $A$ and $B$. 


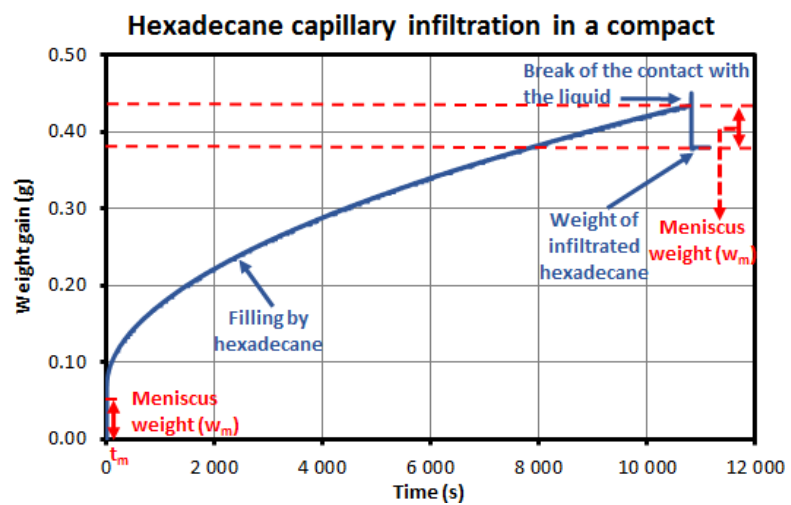

a)

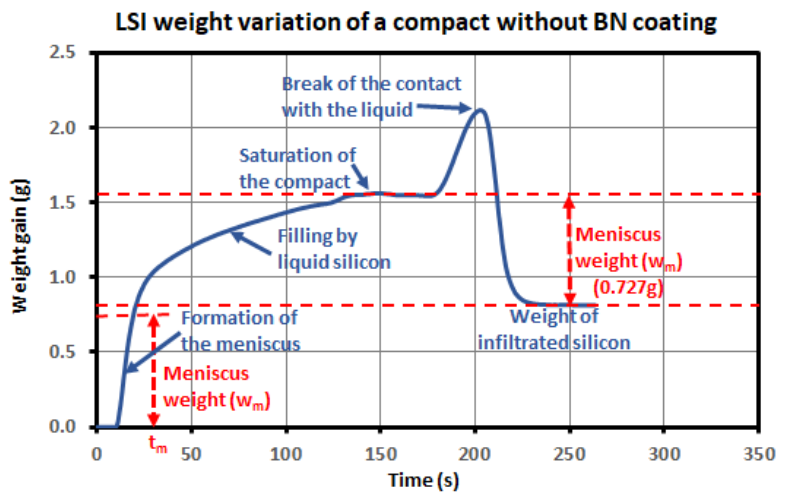

b)

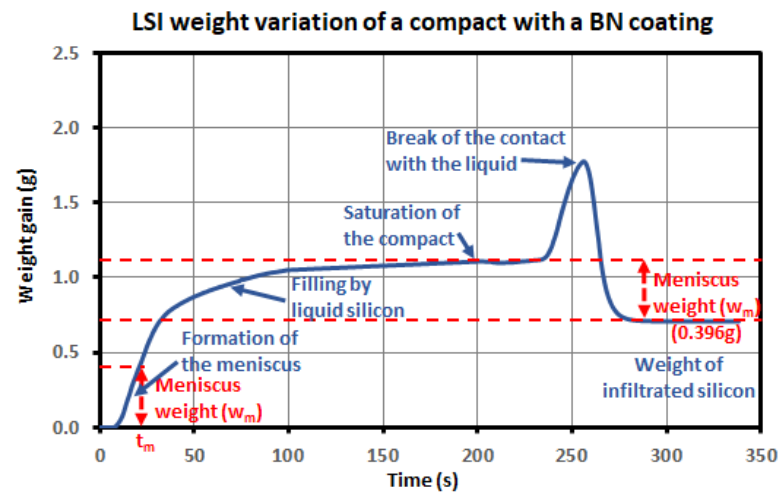

c)

Figure 5: Typical time dependence of capillary infiltration into consolidated compacts:

a) hexadecane weight gain, b) liquid silicon weight gain of uncoated Compact $A$ at $1500^{\circ} \mathrm{C}$ and c) liquid silicon weight gain of $\mathrm{BN}$-coated Compact $\mathrm{B}$ at $1500^{\circ} \mathrm{C}$.

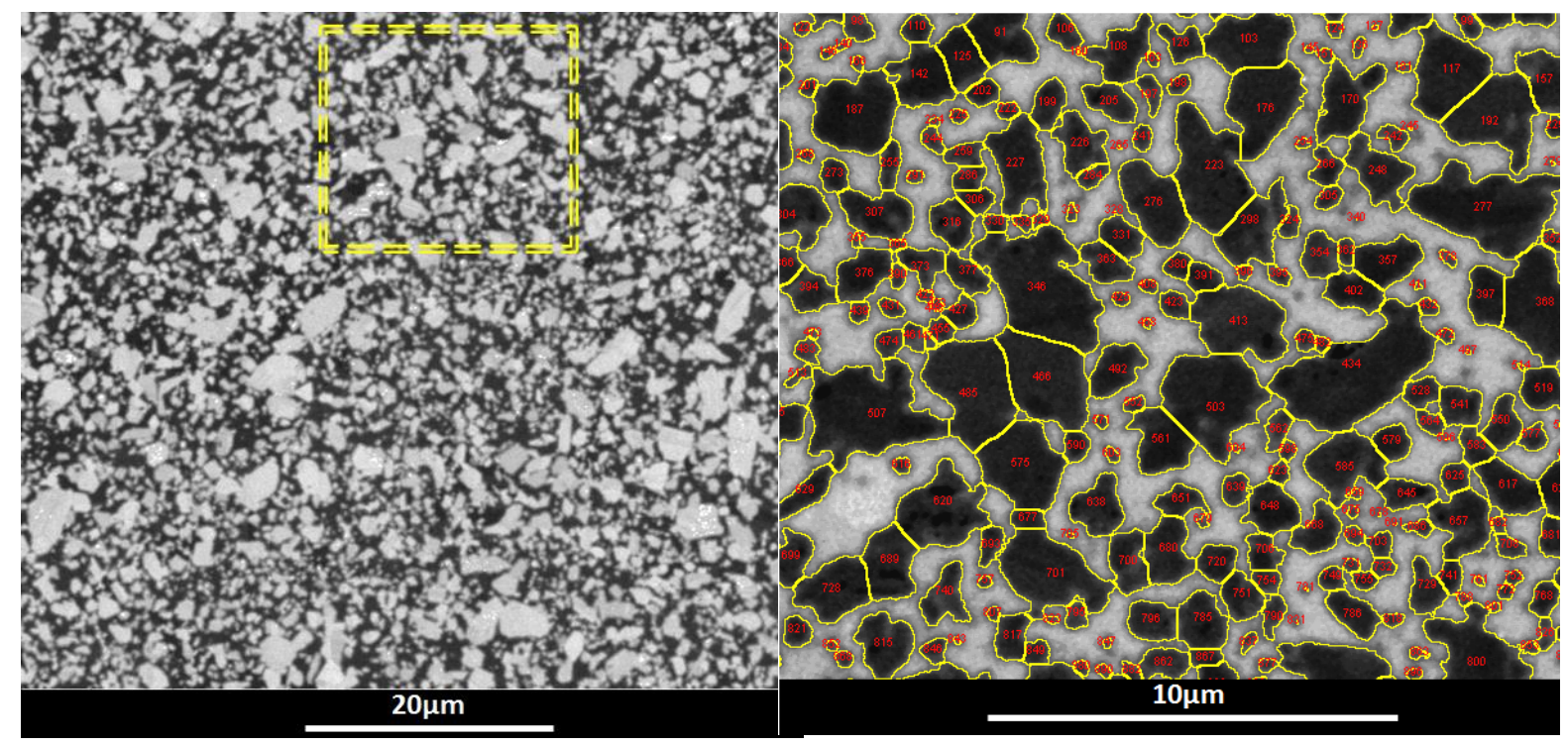

a) b)

Figure 6: Consolidated compacted $\beta$-SiC powder (Compact 0): a) backscattered electrons image and b) focus of the highlighted area of the image analyzed with ImageJ software. 


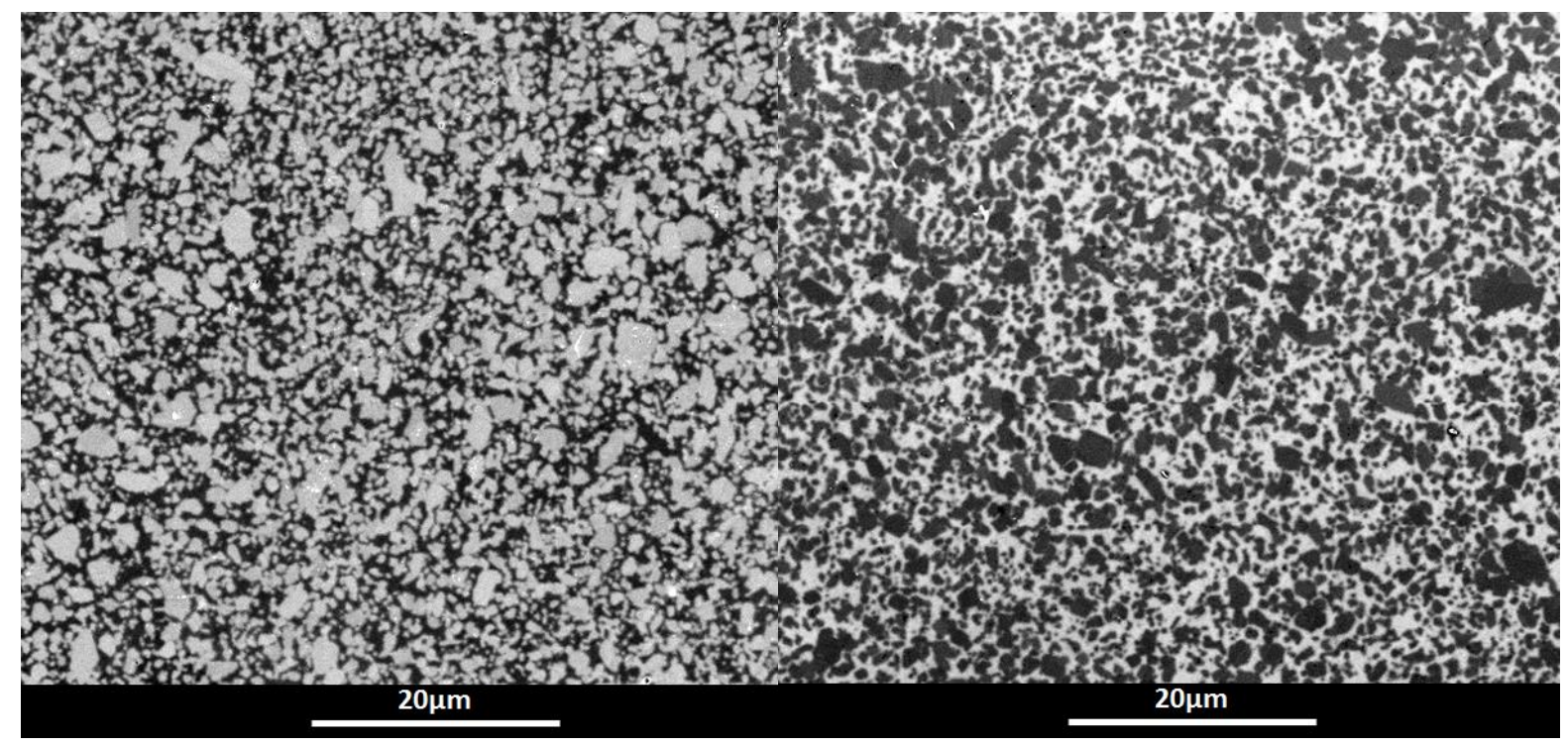

a)

b)

Figure 7: Backscattered electrons image of: a) Compact 1 heat treated at $1500^{\circ} \mathrm{C} / 15 \mathrm{~min}$ and b) Compact $\mathrm{A}$ heat treated at $1500^{\circ} \mathrm{C} / 15 \mathrm{~min}$ and infiltrated by silicon.

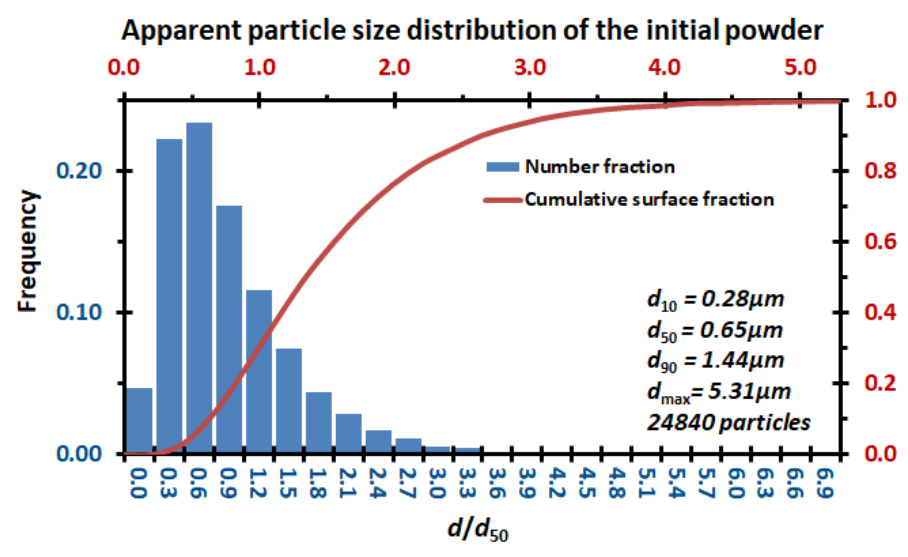

a)

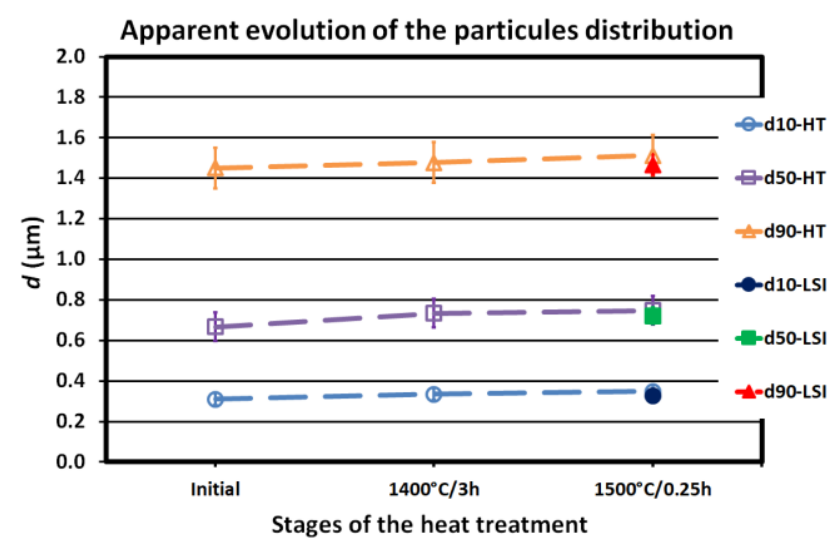

b)

Figure 8: Apparent particles size distribution of the $\beta$-SiC powder and its variation: a) initial distribution and b) variation of the $d_{10}, d_{50}$ and $d_{90}$ values after heating at $1400^{\circ} \mathrm{C}$ for $3 \mathrm{~h}$ and $1500^{\circ} \mathrm{C}$ for $0.25 \mathrm{~h}$ estimated on at least 10000 particles (HT = heat-treated, LSI = liquid silicon infiltrated). 


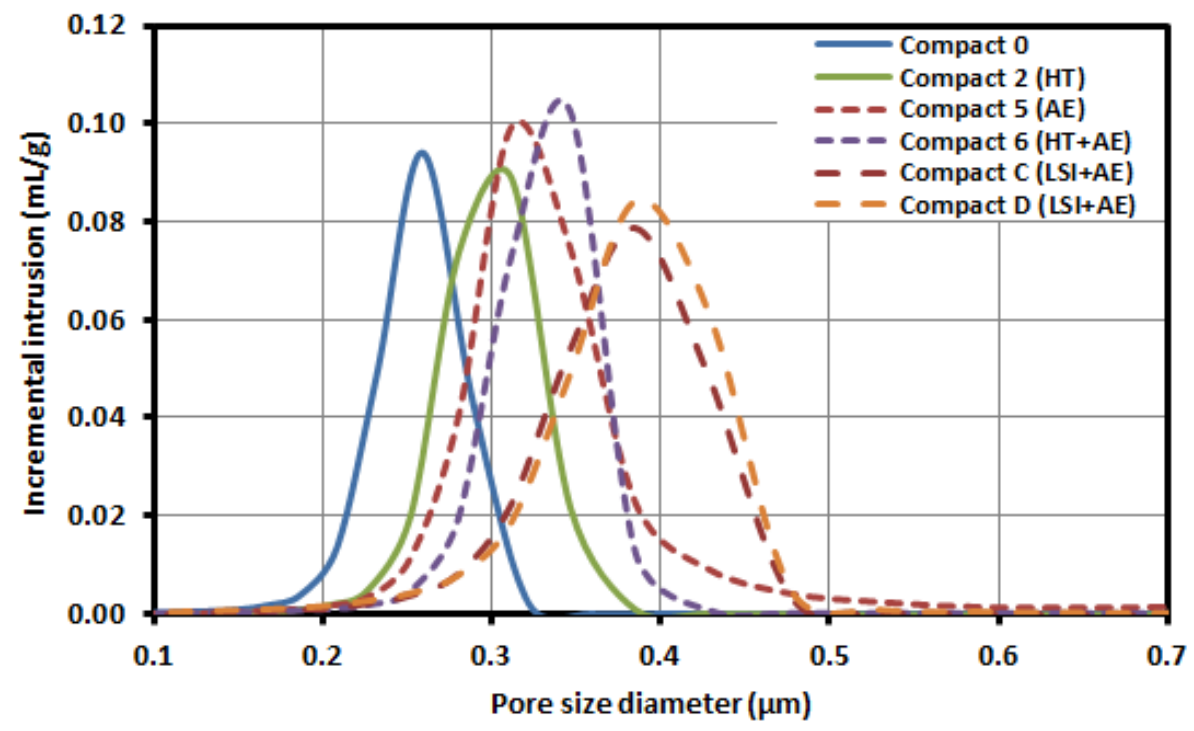

Figure 9: Pore-size distribution of $\mathrm{SiC}$ compacts at the successive stages: consolidation $\left(1400^{\circ} \mathrm{C} / 3 \mathrm{~h}\right)$, heat treatment at $1500^{\circ} \mathrm{C}$ for $0.25 \mathrm{~h}$ without $\mathrm{LSI}$ and heat treatment at $1500^{\circ} \mathrm{C}$ for $0.25 \mathrm{~h}$ with LSI with or without acid etching.

$\left(\mathrm{m}-\mathrm{m}_{\text {meniscus }}\right)^{2} /\left(\varepsilon^{2} \cdot S^{2}\right)$ of hexadecane infiltration

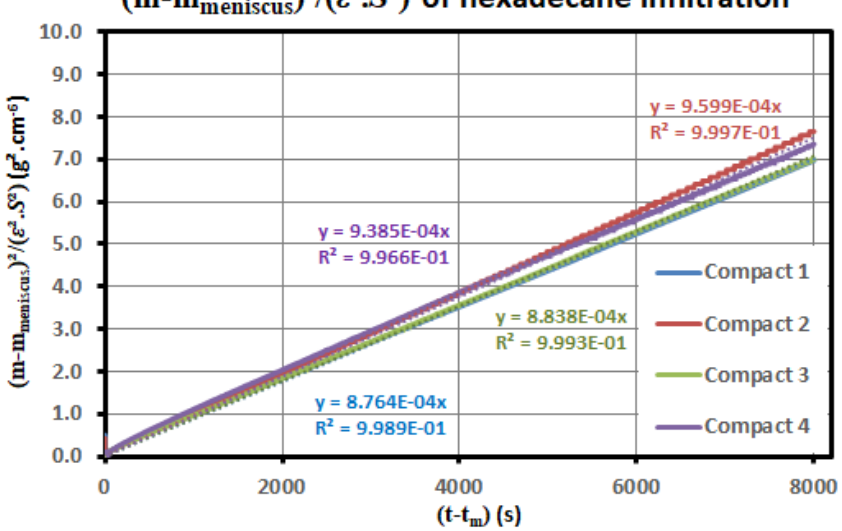

a) $\left(\mathbf{m}-\mathrm{m}_{\text {meniscus }}\right)^{2} /\left(\varepsilon^{2} \cdot S^{2}\right)$ of hexadecane infiltration

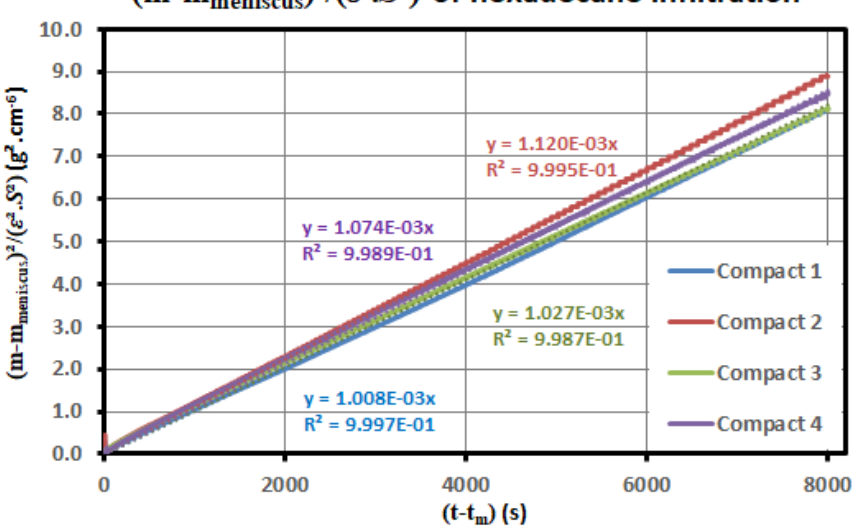

b)

Figure 10: Time dependence of the squared and normalized weight gain curves of infiltration experiments of hexadecane in Compacts 1, 2, 3; and 4: a) before the heat treatment at $1500^{\circ} \mathrm{C}$ for $0.25 \mathrm{~h}$ and $b$ ) after the heat treatment. 
$\left(\mathbf{m}-\mathbf{m}_{\text {meniscus }}\right)^{2} /\left(\varepsilon^{2} \cdot S^{2}\right)$ of hexadecane infiltration

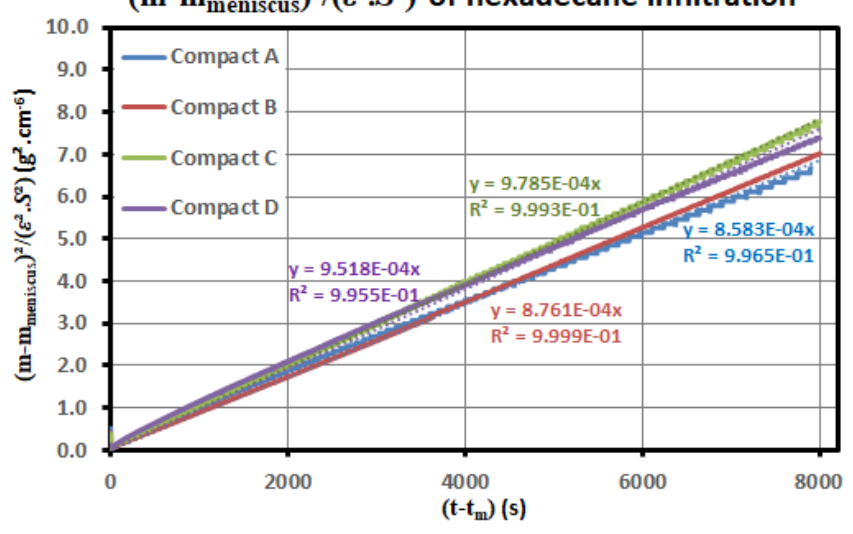

a)

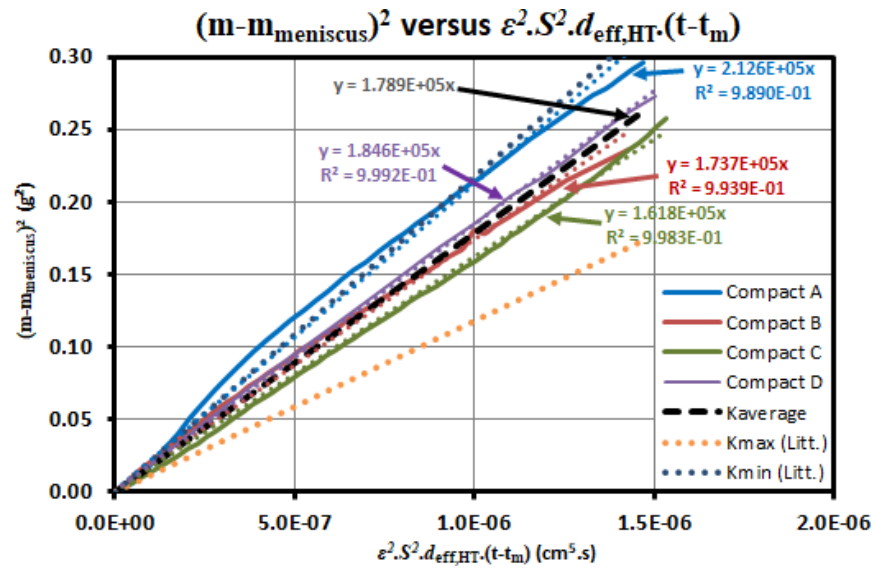

b)

Figure 11: Time dependence of the squared and normalized weight gain curves of infiltration experiments in Compacts A, B, C and D: a) of hexadecane and b) of liquid silicon at $1500^{\circ} \mathrm{C}$.

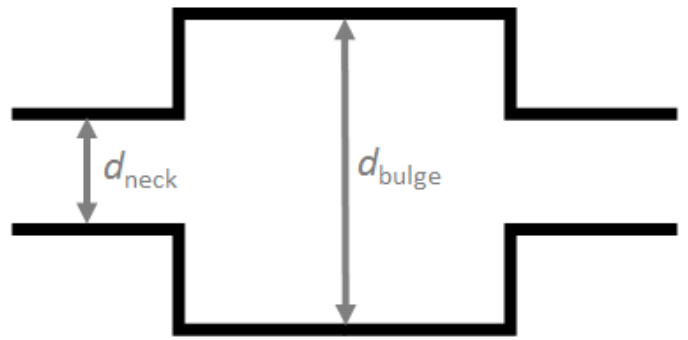

Figure 12: Schematic representation of a two-size capillary repeating unit with pore neck diameter $d_{\text {neck }}$ and pore bulge diameter $d_{\text {bulge }}$ used to describe the porosities of the compacts. 